\title{
AVALIAÇÃO BIOECONÔMICA DO USO DA TORTA DE DENDÊ NA ALIMENTAÇÃO DE VACAS LEITEIRAS
}

\author{
Odislei Fagner Ribeiro Cunha ${ }^{1}$, Jose Neuman Miranda Neiva ${ }^{2}$, Raylon Pereira Maciel ${ }^{1}$, \\ Fabricia Rocha Chaves Miotto ${ }^{2}$, ANA Claudia Gomes Rodrigues NeIVA ${ }^{2}$, JoÃo Restle ${ }^{3}$

\footnotetext{
${ }^{1}$ Pós-graduando da Universidade Federal do Tocantins, Araguaína, TO, Brasil.

${ }^{2}$ Professores Doutores da Universidade Federal do Tocantins, Araguaína, TO, Brasil. - araguaia2007@ gmail.com
} \\ ${ }^{3}$ Professor Visitante Nacional Senior (CAPES) na Universidade Federal do Tocantins, Araguaína, TO, Brasil.
}

\begin{abstract}
O presente trabalho foi desenvolvido objetivando avaliar bioeconomicamente o efeito da inclusão de torta de dendê (TD) na dieta de vacas leiteiras $(0,0 ; 11,34 ; 22,78$ e $34,17 \%)$. Foram avaliadas a produção de leite expressa em $\mathrm{kg} / \mathrm{dia}$ (PL) e em porcentagem do peso vivo (PL\%PV), eficiência alimentar (EA), teores de proteína, gordura, relação gordura:proteína, lactose, sólidos totais (ST), extrato seco desengordurado (ESD) e nitrogênio ureico no leite (NUL). Houve efeito linear decrescente sobre a PL e PL\%PV com a inclusão da TD. A EA aumentou linearmente $(0,008$ pontos $)$ com a inclusão da torta de

dendê. Observou-se redução linear nos teores de proteína e ESD. Já para os teores de gordura, lactose, ST, relação gordura:proteína e PL corrigida para $4 \%$ de gordura expressas em \% do peso vivo não se verificou efeito da inclusão da TD. Houve efeito linear crescente da inclusão da TD nas dietas sobre os teores de NUL. A inclusão de TD na dieta de vacas leiteiras implica em redução da produção de leite, embora não comprometa a sua composição. A utilização da TD deve ser feita com ressalva, pois compromete a produção leiteira e a condição corporal dos animais.
\end{abstract}

PALAVRAS-CHAVE: biocombustíveis; desempenho; ruminante; subprodutos.

\section{BIOECONOMIC EVALUATION OF THE USE OF PALM KERNEL CAKE IN DAIRY COWS FEEDING}

\section{ABSTRACT}

This work was carried out with the purpose of evaluating the bioeconomic effect of the inclusion of palm kernel cake (PKC) to the diet of dairy cows $(0.0,11.34,22.78$ and $34.17 \%)$. We evaluated the milk production expressed in $\mathrm{kg} / \mathrm{day}$ (MP) and in percentage of body weight (MP\%BW), feed efficiency (FE), the contents of protein, fat, fat:protein ratio, lactose, total solids (TS ), defatted dry extract (DDE) and milk urea nitrogen (MUN). A linear decreasing effect was observed on the $\mathrm{MP}$ and MP\%BW with the inclusion of PKC. The FE increased linearly ( 0.008 points) with the inclusion of

KEYWORDS: biofuel; by-products; performance; ruminant.

\section{INTRODUÇÃO}

Nos últimos 15 anos, as regiões Centro-Oeste e Norte aumentaram seu espaço no agronegócio palm kernel cake. There was a linear reduction in protein and DDE contents. As for fat, lactose and TS contents, fat: protein ratio and MP corrected for $4 \%$ of fat expressed in $\%$ of BW there was no effect of the inclusion of PKC. There was a linear increasing effect of the inclusion of PKC to the diets on the levels of MUN. The inclusion of PKC to the diet of dairy cows implies in reduction of milk production, although it does not compromise its composition. The use of PKC should be made with reservation because it compromises milk production and body condition of the animal. nacional, sendo o leite um dos produtos de destaque nesse panorama, principalmente por apresentar vantagens comparativas em relação aos custos de produção. Certamente, se os produtores dessas regiões 
conseguirem produzir leite com custos mais baixos do que as regiões tradicionalmente reconhecidas pela atividade, uma nova configuração para a pecuária de leite nacional será projetada, em longo prazo (GOMES \& FERREIRA FILHO, 2007). Segundo EMBRAPA (2008), a produção de leite na região Norte do Brasil cresceu em média 8,5\% ao ano, de 1998 a 2007, enquanto, no país, esse crescimento foi de 3,9\%.

$\mathrm{O}$ custo de fontes tradicionais de alimentos para suplementação animal, como os grãos de cereais, tem se tornado limitante à rentabilidade dos sistemas de produção. A inclusão de fontes energéticas alternativas em rações para vacas em lactação tem como principal objetivo baixar os custos de alimentação, mantendo-se os níveis de produção de leite (PEDROSO et al., 2009). Dentre as alternativas, os subprodutos oriundos da produção de biodiesel surgem como opção promissora em função do grande volume a ser gerado, pois, com os incentivos governamentais, a produção do biodiesel tende a crescer no Brasil. Dessa forma, espera-se o aumento da oferta de subprodutos que podem ser utilizados na alimentação animal. A torta de dendê é um destes subprodutos, caso esse vegetal seja adotado como matriz energética.

A inclusão de cerca de $10 \%$ de torta de dendê na dieta de vacas lactantes é empregada em vários países e, na Malásia, a inclusão supera 50\% (OSMAN $\&$ HISAMUDDIN, 1999). De acordo com SILVA et al. (2005), a torta de dendê pode substituir o concentrado à base de milho moído e farelo de soja em até $18,81 \%$ da matéria seca da dieta de cabras em lactação, sem reduzir a produção do leite.

A avaliação do valor nutritivo dos alimentos para animais tem sido um desafio para os nutricionistas. A variedade de alimentos que podem e são utilizados na alimentação de ruminantes é grande, mas seu valor nutricional é determinado por complexa interação entre seus constituintes com os microrganismos do trato digestivo, processos de digestão, absorção, transporte e utilização de metabólitos, além da própria condição fisiológica do animal (DUTRA et al., 1997).

Este estudo foi conduzido com o objetivo de avaliar o efeito da inclusão da torta de dendê na dieta de vacas leiteiras sobre a produção e composição do leite, eficiência alimentar e custos com a alimentação dos animais.

\section{MATERIAL E MÉTODOS}

Utilizaram-se oito vacas mestiças, $\left(\begin{array}{lll}1 / 2 & \text { a } & 3 / 4\end{array}\right.$ Holandês x Zebu), com segunda ordem de parição, com 36 meses de idade, $382 \mathrm{~kg}$ de peso vivo médio, com 60 a 90 dias em lactação (DEL) no início do período experimental. Os animais foram distribuídos em dois quadrados latinos $4 \times 4$.

Estipularam-se quatro períodos experimentais com duração de 15 dias cada, sendo 11 dias de adaptação às dietas e quatro dias para coleta de dados, adaptado de SOARES et al. (2004). Os animais receberam quatro dietas contendo $0 ; 11,34 ; 22,78$ e $34,17 \%$ de torta de dendê (TD) com base na matéria seca (MS), obtida através de prensagem mecânica do fruto do dendezeiro (Elaeis guineensis). A TD foi adquirida na Agroindústria Palmasa S/A, no município de Igarapé-Açu, estado do Pará. A Tabela 1 apresenta a composição químico-bromatológica dos ingredientes utilizados.

Tabela 1 - Composição química-bromatológica dos ingredientes utilizados nas dietas experimentais

\begin{tabular}{lcccc}
\hline & \multicolumn{3}{c}{ Ingredientes } \\
\cline { 2 - 5 } Item & Milho & Farelo de soja & Torta de dendê & Cana-de-açúcar \\
\hline Matéria Seca (\%) & 88,77 & 87,23 & 92,54 & 27,00 \\
Proteína Bruta (\%) & 9,06 & 45,85 & 15,42 & 2,15 \\
Fibra em Detergente Neutro (\%) & 14,94 & 15,39 & 71,67 & 56,03 \\
Fibra em Detergente Ácido (\%) & 5,82 & 9,98 & 44,14 & 32,91 \\
Celulose (\%) & 4,73 & 8,74 & 28,98 & 25,66 \\
Hemicelulose (\%) & 9,12 & 5,41 & 27,53 & 23,12 \\
Lignina (\%) & 0,88 & 1,09 & 16,23 & 6,78 \\
NIDN ${ }^{1} \%$ N total) & 9,50 & 4,90 & 80,16 & 34,00 \\
NIDA (\% N total) & 3,80 & 2,81 & 37,24 & 18,43 \\
Carboidratos Não Fibrosos (\%) & 74,97 & 29,3 & 13,47 & 38,77 \\
Extrato Etéreo (\%) & 4,23 & 1,91 & 10,86 & 2,40 \\
Nutrientes Digestíveis Totais (\%) & 87,13 & 81,07 & 61,61 & 63,42 \\
Cinzas (\%) & 1,55 & 6,41 & 3,75 & 2,42 \\
Cálcio (\%) & 0,06 & 0,23 & 0,34 & 0,20 \\
Fósforo (\%) & 0,32 & 0,58 & 0,56 & 0,06 \\
\hline
\end{tabular}

${ }^{1}$ Nitrogênio Insolúvel em Detergente Neutro; ${ }^{2}$ Nitrogênio Insolúvel em Detergente Ácido. 
As dietas foram calculadas para suprir as exigências de mantença e produção de $15 \mathrm{~kg}$ de leite/dia, com 3,6\% de gordura, de acordo com o NRC (2001). O teor de nutrientes digestíveis totais (NDT) para o cálculo das dietas foi estimado a partir da equação do NRC (2001). Todas as dietas foram calculadas na tentativa de serem isoproteicas, com $15 \%$ de proteína bruta, na base da MS, mantendo-se a mesma relação volumoso:concentrado de
43,3:56,7, com base na MS, em todos os tratamentos (Tabela 2). Em função do lote de torta de dendê utilizado apresentar teor de proteína bruta maior que o analisado para formulação das dietas, os teores desse nutriente elevaram-se à medida que se aumentou a inclusão de torta de dendê, não se obtendo, dessa forma, rações isoproteicas conforme planejado inicialmente.

Tabela 2 - Proporção dos ingredientes e composição químico-bromatológica das dietas experimentais

\begin{tabular}{|c|c|c|c|c|}
\hline \multirow{3}{*}{ Item } & \multirow{2}{*}{\multicolumn{4}{|c|}{$\begin{array}{c}\text { Dietas } \\
\text { Níveis de Inclusão de Torta de Dendê } \\
(\% \mathrm{MS})\end{array}$}} \\
\hline & & & & \\
\hline & 0 & 11,34 & 22,78 & 34,17 \\
\hline \multicolumn{5}{|l|}{ Ingredientes } \\
\hline Cana-de-açúcar & 43,30 & 43,30 & 43,30 & 43,30 \\
\hline Farelo de soja & 14,32 & 12,26 & 11,39 & 9,97 \\
\hline Milho grão moído & 39,34 & 29,98 & 19,46 & 9,49 \\
\hline Torta de dendê & 0 & 11,34 & 22,78 & 34,17 \\
\hline Novo bovigold ${ }^{1}$ & 1,21 & 1,24 & 1,22 & 1,22 \\
\hline Ureia+ Sulfato de amônio (9:1) & 1,83 & 1,88 & 1,85 & 1,85 \\
\hline \multicolumn{5}{|c|}{ Composição Bromatológica } \\
\hline Matéria Seca (\%) & 61,02 & 61,60 & 61,98 & 62,25 \\
\hline Proteína Bruta (\%) & 15,15 & 16,80 & 17,03 & 17,64 \\
\hline Fibra em Detergente Neutro (\%) & 38,75 & 41,01 & 46,58 & 51,72 \\
\hline Fibra em Detergente Ácido (\%) & 17,78 & 21,95 & 26,81 & 30,47 \\
\hline Hemicelulose (\%) & 18,40 & 19,71 & 20,80 & 21,60 \\
\hline Carboidratos Totais (\%) & 76,98 & 74,48 & 73,30 & 72,08 \\
\hline Carboidratos não Fibrosos (\%) & 42,03 & 34,45 & 27,82 & 22,83 \\
\hline Celulose (\%) & 13,98 & 16,93 & 20,14 & 22,62 \\
\hline Lignina $(\%)$ & 3,30 & 4,54 & 6,14 & 7,37 \\
\hline Lignina/ Fibra em Detergente Neutro (\% da FDN) & 8,52 & 11,07 & 13,18 & 14,25 \\
\hline Cinzas & 4,50 & 4,46 & 4,42 & 4,31 \\
\hline NIDN (\% N total) & 19,17 & 27,26 & 35,39 & 43,50 \\
\hline NIDA (\% N total) & 9,88 & 13,69 & 17,52 & 23,35 \\
\hline Extrato Etéreo (\%) & 3,37 & 4,26 & 5,26 & 6,97 \\
\hline Cálcio (\%) & 0,64 & 0,36 & 0,42 & 0,53 \\
\hline Fósforo (\%) & 0,50 & 0,29 & 0,32 & 0,43 \\
\hline Nutrientes Digestíveis Totais ${ }^{4}(\%)$ & 72,65 & 70,61 & 67,58 & 66,94 \\
\hline
\end{tabular}

${ }^{1}$ Novo bovigold (níveis/kg produto): P-60g; Ca- 200g; Mg- 20g; S-20g; Na- 70g; K-35g; Cu-700mg; I-40mg; Co-15mg; Fe-700mg; Mn-1.600mg; Zn-2.500mg; Se-19mg; Cr-10mg; F-600mg; BHT-0,125g; VitA-200.000UI; VitE- 1.500UI; VitD3-50.000UI.

As vacas foram confinadas em baias individuais com área de $12 \mathrm{~m}^{2}$, providas de comedouro individual coberto e bebedouro de plástico. A dieta foi oferecida na forma de mistura completa, duas vezes ao dia, às 9:00 h e às 17:00 h, de modo a permitir de 5 a $10 \%$ de sobras. As quantidades de ração oferecida e de sobras foram registradas diariamente, retirando-se uma alíquota, que foi acondicionada em sacos plásticos e congelada. Posteriormente, as amostras foram présecadas, em estufa ventilada a $55^{\circ} \mathrm{C}$ por 72 horas, moídas em peneira de $1 \mathrm{~mm}$, acondicionadas em frasco com tampa e armazenadas para posteriores análises.

As análises de MS, cinzas, extrato etéreo (EE), nitrogênio total (NT), fibra em detergente neutro (FDN) e FDN corrigida para cinza e proteína (FDNcp), fibra em detergente ácido (FDA), lignina, 
cálcio e fósforo nos alimentos, nas sobras e nas fezes foram realizadas no Laboratório de Nutrição Animal da Universidade Federal do Tocantins (UFT), localizado na Escola de Medicina Veterinária e Zootecnia, Campus Universitário de Araguaína, seguindo as recomendações de SILVA \& QUEIROZ (2002).

Os valores dos carboidratos não fibrosos foram obtidos por meio da equação: $\mathrm{CNF}=100-$ $[(\% \mathrm{~PB}-\% \mathrm{~PB}$ da ureia $+\%$ ureia $)+\mathrm{FDNcp}+\%$ $\mathrm{EE}+\%$ Cinzas], proposta por HALL (2000), e os carboidratos totais foram determinados por meio da equação: $100-(\% \mathrm{~PB}+\% \mathrm{EE}+\%$ Cinzas $)$, de acordo com SNIFFEN et al. (1992).

$\mathrm{O}$ teor dos nutrientes digestíveis totais (NDT) da cana-de-açúcar, da torta de dendê e das dietas foram calculados segundo a equação de predição utilizada pelo NRC (2001): NDT $=\left\{\mathrm{CNF}_{\mathrm{vd}}\right.$ $\left.+\mathrm{PB}_{\mathrm{vd}}+\left(2,25 \times \mathrm{AG}_{\mathrm{vd}}\right)+\mathrm{FDN}_{\mathrm{vd}}\right\}-7$, sendo: $\mathrm{CNF}_{\text {verdadeiramente digestivel }}=0,98 \times \mathrm{CNF} \times \mathrm{PAF}$; $\mathrm{PB}_{\text {verdadeiramente digestível }}$ (para forragens) $=\mathrm{PB} \times \exp \{-$ $1,2 \times(\mathrm{PIDA} / \mathrm{PC})\} ; \mathrm{PB}_{\text {verdadeiramente digestivel (para }}$ concentrados $)=\{1-(0,4 \times(\mathrm{PIDA} / \mathrm{PB}))\} \times \mathrm{PB}$; $\mathrm{AG}_{\text {verdadeiramente digestível }}=(\mathrm{EE}-1)$, se $\mathrm{EE}<1$, então $\mathrm{AG}$ $=0 ; \mathrm{FDN}_{\text {verdadeiramente digestível }}=0,75 \times\left(\mathrm{FDN}_{\mathrm{n}}-\mathrm{L}\right) \times\{1$ - $(\mathrm{L} / \mathrm{FDN})^{0,667}$ \}, em que PIDA = nitrogênio insolúvel em detergente ácido x 6,25; $\mathrm{AG}=$ Ácidos graxos, $\mathrm{L}=$ lignina, e FDNn $=$ FDN - PIDN, PIDN $=$ nitrogênio insolúvel em detergente neutro x 6,25, $\mathrm{PAF}=$ fator de ajuste para processamento, sendo utilizado o fator 1 para a torta de dendê e a cana-deaçúcar. Os valores de nutrientes digestíveis totais observados foram estimados para as diferentes dietas pela equação: $\mathrm{NDT}_{\mathrm{OBS}}=\mathrm{PB}_{\text {digestivel }}+\left(\mathrm{EE}_{\text {digestível }} \mathrm{x}\right.$ $2,25)+\mathrm{FDN}_{\text {digestível }}+\mathrm{CNF}_{\text {digestível }}$ (SNIFFEN et al., 1992).

A ordenha dos animais foi realizada manualmente com presença do bezerro, duas vezes ao dia, às $6: 30 \mathrm{~h}$ e às $16: 30 \mathrm{~h}$. Avaliou-se a produção de leite expressa em $\mathrm{kg} / \mathrm{dia}$ e em porcentagem do peso vivo, bem como a eficiência alimentar. A produção de leite (PL) foi registrada com auxílio de balança digital, na ordenha da manhã e da tarde, do $11^{\circ}$ ao $15^{\circ}$ dia de cada período experimental. A produção de leite em porcentagem do peso vivo foi calculada pela relação entre PL e o peso médio da vaca no respectivo período. Foram coletadas amostras de leite, na $2^{\mathrm{a}}$ ordenha do $14^{\mathrm{o}}$ dia e $1^{\mathrm{a}}$ ordenha do $15^{\circ}$ dia de cada período experimental. As amostras foram misturadas proporcionalmente e compostas por animal, acondicionadas em frascos plásticos com conservante (Bronopol), mantidas em temperatura entre 2 e $6^{\circ} \mathrm{C}$ e enviadas à Clínica do Leite na ESALQ/USP, em Piracicaba-SP, para análise dos teores de proteína, gordura, lactose, extrato seco desengordurado e sólidos totais pelo processo de infravermelho, por meio do analisador Bentley 2000 (Bentley Instruments $\left.{ }^{\circledR}\right)$ e nitrogênio ureico pelo analisador ChemSpec 150 (Bentley Instruments $\left.{ }^{\circledR}\right)$.

As vacas foram pesadas no início e fim de cada período experimental, sempre após a ordenha da manhã e antes de receber a dieta, para acompanhamento do peso corporal. O ganho de peso médio diário foi obtido através da diferença de peso da vaca no início e no fim do período para cada tratamento, obtendo ao final do experimento o ganho de peso médio diário em cada tratamento.

Para determinar os custos, considerou-se que os tratamentos foram aplicados em sistemas de produção que demandavam os mesmos insumos (instalações, mão-de-obra, equipamentos, entre outros), diferindo apenas quanto às dietas fornecidas. Portanto, para quantificar o diferencial de custos entre um tratamento e outro, utilizou-se somente o cálculo das despesas com alimentação dos animais (PEREIRA et al., 2003).

Na Tabela 3, demonstram-se os valores de mercado dos ingredientes utilizados na alimentação das vacas durante o período experimental e o preço recebido pelo $\mathrm{kg}$ de leite praticado no mês de janeiro de 2010, no mercado regional de Araguaína-TO. Os preços dos ingredientes foram convertidos para MS de acordo com seu respectivo teor de MS. Considerou-se para custo o total de alimento fornecido por vaca. A margem bruta foi obtida subtraindo-se a receita bruta (produção em $\mathrm{kg}$ de leite $\times$ preço do leite ao produtor) pelo custo diário da alimentação. Já o custo da alimentação por quilograma de leite produzido foi calculado pela divisão do custo com alimentação (R $\$ / v a c a / d i a)$ pela produção diária de leite (kg/vaca/dia).

Tabela 3 - Custos médios dos ingredientes das dietas e do litro do leite

\begin{tabular}{lc}
\hline Ingredientes & $\mathrm{R} \$ / \mathrm{kg}$ de MS \\
\hline Cana-de-açúcar & 0,15 \\
Farelo de soja & 0,93 \\
Milho moído & 0,41 \\
Torta de dendê & 0,40 \\
Novo Bovigold & 1,90 \\
Ureia & 1,10 \\
Sulfato de amônio & 0,90 \\
\hline $\mathrm{R} \$ /$ Kg do leite & 0,45 \\
\hline
\end{tabular}

As análises estatísticas foram realizadas utilizando-se o programa computacional SAS (2007). Foram realizadas análises do modelo de regressão 
pelo procedimento REG para testar o efeito linear e quadrático dos níveis de inclusão da torta de dendê na dieta.

\section{RESULTADOS E DISCUSSÃO}

A produção de leite diminuiu linearmente $(\mathrm{P}<0,01)$ com a inclusão de TD na dieta (Tabela 4). Para cada $1 \%$ de inclusão de TD na dieta observouse redução de $0,05 \mathrm{~kg}$ de leite/dia. Pela equação de regressão, observa-se que a PL no nível mais elevado de inclusão da TD $(34,17 \%)$ foi $17,15 \%$ inferior ao da dieta padrão. A redução da PL provavelmente ocorreu devido ao baixo teor de carboidratos não fibrosos (CNF) da TD, pois a sua adição nas dietas resultou em queda do teor desse nutriente (Tabela 2), com consequente diminuição dos nutrientes digestíveis totais (NDT; Tabela 2).

Outro aspecto relevante é a diminuição no consumo de matéria seca que foi observado com a adição de TD. Conforme pode ser visto na Tabela 4, para cada $1 \%$ de inclusão de TD às dietas, houve redução de $0,15 \mathrm{~kg}$ de matéria seca por vaca/dia. Esse fato, somado à redução nos teores de NDT, justificam a redução na produção de leite à medida que se adiciona a TD às dietas.

Tabela 4 - Consumo, produção leiteira e composição do leite de vacas leiteiras recebendo dietas contendo níveis crescentes de inclusão de torta de dendê

\begin{tabular}{|c|c|c|c|c|c|c|c|}
\hline \multirow{2}{*}{ Item } & \multicolumn{4}{|c|}{ Níveis de torta de dendê (\%) } & \multirow{2}{*}{ Regressão } & \multirow{2}{*}{$\mathrm{R}^{2}$} & \multirow{2}{*}{$\% \mathrm{CV}$} \\
\hline & 0 & 11,34 & 22,78 & 34,17 & & & \\
\hline CMS (kg/dia) & 11,82 & 12,79 & 9,04 & 7,21 & $\hat{Y}=12,85-0,15 x * *$ & 0,43 & 22,56 \\
\hline PL (kg/dia) & 9,39 & 10,28 & 8,62 & 7,90 & $\hat{\mathrm{Y}}=9,97-0,05 \mathrm{x}^{* *}$ & 0,27 & 12,85 \\
\hline PL \%PV $(\%)^{1}$ & 2,43 & 2,64 & 2,22 & 2,07 & $\hat{\mathrm{Y}}=2,57-0,01 \mathrm{x}^{* *}$ & 0,22 & 13,80 \\
\hline PLCG $\%$ PV $(\%)^{1}$ & 2,04 & 2,31 & 1,86 & 1,80 & $\hat{\mathrm{Y}}=2,0$ & Ns & 20,28 \\
\hline $\mathrm{EA}^{2}(\mathrm{~kg})$ & 0,70 & 0,72 & 0,80 & 0,98 & $\hat{\mathrm{Y}}=0,66+0,008 \mathrm{x}^{* *}$ & 0,26 & 22,44 \\
\hline Gordura (\%) & 2,95 & 3,19 & 3,31 & 3,18 & $\hat{\mathrm{Y}}=3,15$ & Ns & 30,22 \\
\hline Proteína (\%) & 3,58 & 3,30 & 2,29 & 3,12 & $\hat{\mathrm{Y}}=3,53-0,01 \mathrm{x} * *$ & 0,27 & 7,98 \\
\hline Relação Gordura/Proteína & 0,82 & 0,95 & 0,99 & 1,01 & $\hat{\mathrm{Y}}=0,94$ & Ns & 25,94 \\
\hline Lactose $(\%)$ & 4,71 & 4,77 & 4,67 & 4,68 & $\hat{\mathrm{Y}}=4,70$ & Ns & 3,98 \\
\hline ST $(\%)^{3}$ & 12,27 & 12,17 & 11,84 & 11,93 & $\hat{Y}=12,05$ & Ns & 9,15 \\
\hline $\operatorname{ESD}(\%)^{4}$ & 9,33 & 8,99 & 8,92 & 8,76 & $\hat{\mathrm{Y}}=9,26-0,01 \mathrm{x}^{* *}$ & 0,47 & 2,39 \\
\hline $\operatorname{NUL}(\mathrm{mg} / \mathrm{dl})^{5}$ & 19,64 & 22,24 & 24,57 & 25,93 & $\hat{\mathrm{Y}}=19,92+0,18 \mathrm{x} * *$ & 0,34 & 14,75 \\
\hline
\end{tabular}

**1\% de probabilidade; ns = não significativo; $\mathrm{R}^{2}=$ coeficiente de determinação; $\mathrm{CV}=$ coeficiente de variação; ${ }^{1}$ Produções de leite com (PLCG\%PV) e sem (PL\%PV) correção para 4\% de gordura expressas em \% do peso vivo (PV); ${ }^{2}$ Eficiência alimentar (kg de leite/kg de MS consumida); ${ }^{3}$ Sólidos totais; ${ }^{4}$ Extrato seco desengordurado; ${ }^{5}$ Nitrogênio ureico no leite.

Não houve efeito $(\mathrm{P}>0,05)$ dos níveis de inclusão de TD sobre a produção de leite em porcentagem do peso vivo (PLCG \%PV), com valor médio de $2 \%$ do PV. Já a produção de leite (não corrigida para $\%$ de gordura) expressa em \%PV decresceu linearmente $(\mathrm{P}<0,01)$ e, para cada $1 \%$ de inclusão da TD, observou-se redução de 0,01 pontos percentuais, seguindo o mesmo comportamento observado para PL. A determinação desse parâmetro possibilita caracterizar melhor a eficiência produtiva quando se avaliam subprodutos na dieta de vacas leiteiras, em virtude da variação do tamanho corporal das vacas utilizadas nos diferentes sistemas de produção existentes no Brasil.
A adição de TD às dietas elevou linearmente $(p<0,01)$ a eficiência alimentar (EA), observando-se que para cada $1 \%$ de inclusão houve um aumento da EA de 0,008 pontos percentuais (Tabela 4). O aumento linear da EA provavelmente ocorreu devido à mobilização das reservas corporais, verificada pela queda no ganho de peso médio diário (Tabela 5) para produção de leite, associada à redução do consumo, que proporcionou melhor aproveitamento dos nutrientes e, consequentemente, aumento da eficiência alimentar.

De acordo com HUTJENS (2004), valores menores que 1,3 indicam baixa EA, que pode ocorrer em rebanhos com baixo potencial genético para 
produção de leite ou submetidos a estresse, vacas primíparas ou em final de lactação e/ou gestação e ainda alimentadas com volumosos de baixa qualidade. No presente estudo, provavelmente, o uso da cana-de-açúcar um volumoso de qualidade média, associado à utilização de animais mestiços leiteiros reconhecidamente de menor potencial em relação às raças leiteiras especializadas podem ter levado à menor EA, a qual apresentou valores inferiores a 1,3.

Não houve efeito $(\mathrm{P}>0,05)$ da inclusão da TD sobre o percentual de gordura do leite, com média de 3,15\% (Tabela 4). PEDROSO et al. (2009) avaliaram a substituição do milho em grão por farelo de glúten de milho na dieta de vacas em lactação e também não observaram efeito sobre o teor de gordura do leite, embora esperassem maior síntese de gordura, uma vez que a inclusão do farelo de glúten de milho nas dietas elevou a concentração de FDN e reduziu concentração de amido nas rações. SILVA (2006) avaliou a substituição do farelo de trigo pela torta de babaçu na alimentação de vacas mestiças em lactação e não observou efeito sobre o teor de gordura do leite, atribuindo esse resultado ao fato de a substituição não ter influenciado o consumo de FDN.

Os teores de proteína do leite reduziram linearmente $(\mathrm{p}<0,01)$ com a inclusão da TD na dieta, verificando-se redução de $0,01 \%$ para cada $1 \%$ de inclusão da TD. A redução no teor de proteína do leite provavelmente ocorreu devido ao menor teor de CNF nas dietas (Tabela 2) que continham níveis mais elevados da TD, podendo, dessa forma, limitar a síntese de proteína microbiana no rúmen. Com redução no aporte de proteína que chega ao intestino delgado há menor disponibilidade de aminoácidos na glândula mamária para síntese de proteína.

A magnitude da variação nos teores de proteína e gordura do leite não foi suficiente para ocasionar efeito $(\mathrm{P}>0,05)$ sobre a relação gordura: proteína do leite com a inclusão da TD nas dietas, observando-se valor médio de 0,94 . Não se observou efeito $(\mathrm{P}>0,05)$ da inclusão da TD sobre os teores de lactose e sólidos totais (ST) do leite, com valores médios de $4,70 \%$ e $12,05 \%$, respectivamente. A fibra e os CNF dietéticos não interferiram no teor de gordura e, consequentemente, no teor de ST, uma vez que a gordura é o componente do leite que apresenta maiores variações. Já a lactose é o componente que apresenta concentração mais estável, sendo essencialmente uma constante de $4,85 \%$ do leite (NRC, 2001).

$\mathrm{O}$ teor de extrato seco desengordurado (ESD) do leite decresceu linearmente $(\mathrm{P}<0,01)$ com a inclusão da TD e, para cada $1 \%$ de inclusão de TD na dieta, observou-se redução de 0,01 pontos percentuais para essa característica. Como não houve efeito da inclusão da TD sobre o teor de lactose do leite, provavelmente a redução da proteína foi responsável pela redução do ESD.

O percentual de nitrogênio ureico no leite (NUL) aumentou linearmente $(p<0,01)$ com a inclusão da TD nas dietas. Para cada $1 \%$ de inclusão da TD ocorreu aumento de $0,18 \mathrm{mg} / \mathrm{dl}$ de NUL. O aumento no teor de NUL possivelmente ocorreu devido à redução na disponibilidade de energia no rúmen, pois a inclusão da TD reduziu o NDT das dietas. Isso pode ocorrer quando carboidratos de fermentação rápida são substituídos por subprodutos ricos em FDN, resultando em diminuição da quantidade de nitrogênio capturado pelos microorganismos ruminais para síntese de proteína microbiana e aumento da passagem de nitrogênio amoniacal para a corrente sanguínea.

Os níveis de NUL observados estão acima do limite de 10 a $14 \mathrm{mg} / \mathrm{dl}$ (Tabela 4) proposto por DePETERS \& FERGUSON (1992). De acordo com a equação de regressão, houve aumento de $30,87 \%$ do NUL da dieta padrão para o nível de $34,17 \%$ de inclusão da TD, o que demonstra que houve limitações quanto ao teor de carboidratos fermentáveis no rúmen para que houvesse adequado sincronismo com a proteína dietética.

Outro agravante foi o elevado NUL observado nos animais recebendo a dieta padrão, o que pode ser atribuído ao baixo teor de CNF $(38,77 \%)$ da cana-de-açúcar utilizada no presente estudo, estando abaixo de $44,21 \%$, valor médio apresentado por VALADARES FILHO et al. (2001) nas tabelas de composição de alimentos para ruminantes. GUSTAFSSON \& PALMQUIST (1993) observaram maior tempo para coagulação do queijo oriundo de leite com altas concentrações de nitrogênio não proteico. Os autores ainda ressaltam que, embora a maioria dos países, mesmo os desenvolvidos, ainda não utilize pagamento do leite em função do teor de proteína verdadeira, essa é uma tendência que deve ser rapidamente revertida, o que resultará em perdas econômicas aos produtores não especializados.

Os custos com alimentação, receita, margem bruta, custo por quilograma de leite produzido e ganho de peso médio diário são apresentados na Tabela 5. Verificou-se diminuição do custo com alimentação com o aumento da inclusão da TD nas dietas, porém os animais perderam peso no nível máximo de inclusão desse subproduto 
Tabela 5 - Médias diárias para custo com alimentação, receita e margem bruta e custo por kg de leite e ganho de peso médio diário das vacas em função das dietas experimentais

\begin{tabular}{|c|c|c|c|c|}
\hline \multirow{3}{*}{ Característica } & \multicolumn{4}{|c|}{ Dietas } \\
\hline & \multicolumn{4}{|c|}{$\begin{array}{l}\text { Níveis de inclusão de torta de dendê } \\
(\% \mathrm{MS})\end{array}$} \\
\hline & 0,0 & 11,34 & 22,78 & 34,17 \\
\hline \multicolumn{5}{|l|}{ A - Custo com alimentação } \\
\hline Dieta total oferecida (kg MS/vaca/ dia) & 12,41 & 13,43 & 9,49 & 7,57 \\
\hline Custo da dieta (R\$/ kg MS) & 0,40 & 0,39 & 0,38 & 0,28 \\
\hline Custo alimentação ( $\mathrm{R}$ /vaca/ dia) & 4,99 & 5,25 & 3,65 & 2,15 \\
\hline \multicolumn{5}{|l|}{ B - Receita bruta } \\
\hline Produção de leite (kg/ dia) & 9,39 & 10,28 & 8,62 & 7,90 \\
\hline Preço pago ao produtor ( $\mathrm{R} \$ / \mathrm{kg}$ do leite) & 0,45 & 0,45 & 0,45 & 0,45 \\
\hline Receita bruta (R $\$ /$ vaca/ dia) & 4,23 & 4,63 & 3,88 & 3,56 \\
\hline $\mathrm{C}$ - Margem bruta ( $\mathrm{R} \$$ vaca/ dia) & $-0,77$ & $-0,63$ & 0,23 & 1,41 \\
\hline D - Custo da alimentação por kg de leite produzido & 0,53 & 0,51 & 0,42 & 0,27 \\
\hline E - Ganho médio diário (kg/ vaca/dia) & 0,16 & 0,247 & 0,081 & $-0,120$ \\
\hline
\end{tabular}

Através da avaliação dos custos com alimentação e margem bruta, verifica-se que as dietas com $0,0 \%$ e $11,34 \%$ de TD são economicamente inviáveis, pois a margem bruta foi negativa. Já a inclusão de $34,17 \%$ de TD resulta em perda de peso dos animais e, dessa forma, nenhum desses três tratamentos é desejável em sistemas de produção biológica e economicamente sustentáveis.

RANGEL et al. (2008) enfatizaram que, em avaliação econômica de dietas para vacas leiteiras, a não consideração do peso vivo pode induzir superestimação das dietas, tendo em vista que as variações negativas de peso indicam ocorrência de mobilização das reservas corporais, o que leva ao comprometimento do desempenho reprodutivo e produtivo dos animais.

O aumento na eficiência alimentar (Tabela 4) associado ao ganho de peso viabilizou o uso da TD no nível de inclusão de $22,78 \%$, com margem bruta de $\mathrm{R} \$ 0,23$, o que significa que a exploração se remunera e sobrevive, pelo menos, em curto prazo. No entanto, deve-se atentar para outros aspectos verificados, como a redução no consumo de matéria seca e, consequentemente, de importantes nutrientes, conforme observado por CUNHA (2010). O referido autor, utilizando os mesmos animais e dietas do presente estudo, observou redução nos consumos de MS, PB, CNF, EE e NDT. É provável que, em longo prazo, a inclusão da TD às dietas comprometa o estado fisiológico geral do rebanho e, principalmente, o desempenho reprodutivo do mesmo.

A redução do custo de alimentação com a dieta com inclusão de $34,17 \%$ de TD associada ao baixo CMS possibilitou, para esse tratamento, menor custo com alimentação por kg de leite produzido. No entanto, a melhor margem bruta observada para esse tratamento deve-se à perda de peso $(-0,120 \mathrm{~kg} / \mathrm{dia})$ apresentada, o que resultou em mobilização das reservas corporais nas vacas. Essa situação não é desejável, pois a perda de peso trará prejuízos econômicos, principalmente pelo aumento do intervalo de partos.

\section{CONCLUSÃO}

A inclusão de torta de dendê na dieta de vacas leiteiras implica redução da produção de leite. Embora ocorra redução nos custos de produção com a inclusão da torta de dendê, concomitantemente, ocorre perda de peso dos animais, o que compromete os índices reprodutivos e a futura lactação da vaca.

\section{REFERÊNCIAS}

CUNHA, O.F.R. Consumo, digestibilidade aparente dos nutrientes, produção e composição do leite de vacas leiteiras alimentadas com níveis de inclusão de torta de dendê (Elaeais guineensis) na dieta. 2010. 66f. Dissertação (Mestrado em Ciência Animal Tropical). Universidade Federal do Tocantins, Araguaína. Disponivel 
http://www.dominiopublico.gov.br/pesquisa/DetalheObra Form.do?select_action $=\&$ co_obra $=182139$. Acesso em: 03/02/2012

DePETERS, E. J.; FERGUSON, J. D. Nonprotein nitrogen and protein distribution in the milk of cows. Journal of Dairy Science, v. 75, n. 11, p. 3192-3209, 1992.

DUTRA, A.R.; QUEIROZ, A.C.; PEREIRA, J.C.; VALADARES FILHO, S. C., THIEBAUT, J. T. L., MATOS, F. N., RIBEIRO, C. V. D. M. Efeitos dos níveis de fibra e das fontes de proteínas sobre a síntese de compostos nitrogenados microbianos em novilhos. Revista Brasileira de Zootecnia, v.26, n.4, p.797-805, 1997.

EMBRAPA - Empresa Brasileira de Pesquisa Agropecuária. Informações técnicas: Leite em números (Produção). 2008. Disponível em: http: //www.cnpgl.embrapa.br/nova/informacoes

/estatisticas/estatisticas.php. Acesso: 01/01/2010.

GOMES, A.L.; FERREIRA FILHO, J.B.S. Economias de escala na produção de leite: Uma análise dos Estados de Rondônia, Tocantins e Rio de Janeiro. Revista de Economia e Sociologia Rural, vol. 45, n.03, p. 591-619, 2007.

GUSTAFSSON, A.H.; PALMQUIST, D.L. Diurnal variation of rumen ammonia, sérum urea, and milk urea in dairy cows at high and low yields. Journal of Dairy Science, v.76, p.475-484, 1993.

HALL, M.B. Calculation of non-structural carbohydrate content of feeds that contain non-protein nitrogen. Gainesville: University of Florida, p.A-25 (Bulletin, 339). 2000.

HUTJENS, M.F. Enhancing profitability through setting strategic feed efficiency targets. In: WESTERN CANADIAN DAIRY SEMINAR - Advances in Dairy Technology, 2004, Edmonton. Proceedings... Edmonton: University of Alberta, 2004. v.16, p.23-27. Disponível em http://www.wcds.ca/proc/2004/Manuscripts/23Hutjens.pdf , acesso em 25 set. 2012.

NRC - National Research Council. Nutrient requirements of dairy cattle. 7.ed. Washington, D.C.: National Academy Press, 2001. 381p.

OSMAN, A; HISAMUDDIN, M A. Oil palm and palm oil products as livestock feed. Palm Oil Familiarization Programme. Palm Oil Research Institute of Malaysia, Bangi. 12 p. 1999.

PEDROSO, A. M.; SANTOS, F. A. P.; BITTAR, C. M. Substituição do milho em grão por farelo de glúten de milho na ração de vacas em lactação em confinamento. Revista Brasileira de Zootecnia, v.38, n.8, p. 1614-1619, 2009.

PEREIRA, J. C.; SILVA, P. R. C.; CECON, P. R. RESENDE FILHO, M. A.; OLIVEIRA, R. L. Cama de frango e suplemento à base de microbiota ruminal em dietas de novilhas leiteiras: desempenho produtivo e avaliação econômica. Revista Brasileira de Zootecnia. v.32, n.3, p. 653-662, 2003.

RANGEL, A.H. N.; CAMPOS, J. M. S.; BRITO, A.F.; BRAGA, A. P.; LIMA, R. N. Análise econômica da alimentação de vacas leiteiras com cana-de-açúcar corrigida com farelo de soja ou uréia. Revista Caatinga, v.21, n.2, p.73-75, 2008.

SILVA, D. J. QUEIROZ, A. C. Análise de alimentos (métodos químicos e biológicos). 2 ed. Viçosa,: Universidade Federal de Viçosa,2002. 165p.

SILVA, H. G. O.; PIRES, A. J. V; SILVA, F. F.; VELOSO, C. M. ; CARVALHO, G. G. P.; CESÁRIO, A. S.. SANTOS, C. C. Farelo de cacau (Theobroma cacao L.) e torta de dendê (Elaeis guineensis, Jacq) na alimentação de cabras em lactação: consumo e produção de leite. Revista Brasileira de Zootecnia, v. 34, n. 5, p.1786-1794, 2005.

SILVA, T. C. P. Substituição do farelo de trigo pela torta de babaçu na alimentação de vacas mestiças em lactação. 2006. 30f. Dissertação (Mestrado em Zootecnia). Universidade Federal Rural de Pernambuco, Recife. Disponível em: http://www.dominiopublico.gov.br/pesquisa/ DetalheObraForm.do?select_action=\&co_obra=33737.

Acesso em: 02/12/2011

SOARES, C. A.; CAMPOS, J. M. S.; VALADARES FILHO, S. C.; VALADARES, F. R. D.; MENDONÇA, S. S.; QUEIROZ, A. C.; LANA, R. P. Consumo, digestibilidade aparente, produção e composição do leite de vacas leiteiras alimentadas com farelo de trigo. Revista Brasileira de Zootecnia, v.33, n.6, p.2161-2169, 2004 (Supl. 2).

SNIFFEN, C.J., OCONNOR, J.D., VAN SOEST, P.J. A net carbohydrate and protein system for evaluating caule diets. 2. Carbohydrate and protein availability. Journal of Animal Science, v.70, n.11, p.3562-3577, 1992

STATISTICAL ANALYSES SYSTEM - SAS. User's Guide Statistics. Cary, N.C.: SAS Institute, 2007.

VALADARES FILHO, S.C.; ROCHA JR., V.R.; CAPPELLE, E.R. Tabelas brasileiras de composição de alimentos para bovinos. Viçosa: Universidade Federal de Viçosa, 2001. 297p. 